\title{
Staffing and Scheduling Emergency Rooms in Two Public Hospitals: A Case Study
}

\author{
Sabah M. Al-Najjar (Corresponding Author) \\ Professor of Management \\ Department of Business Management, College of Administration and Economics \\ University of Baghdad, Baghdad, Iraq \\ Tel: +964-7709-726-485Ｅ-mail: sabanajar@yahoo.com
}

Samir Hussain Ali

Instructor of Management

Department of Management, Alturath College

Almansour, Baghdad, Iraq

Tel: +964-7700-688-555_E-mail: samere83@yahoo.com

Received: February 24, $2011 \quad$ Accepted: March 16, $2011 \quad$ doi:10.5430/ijba.v2n2p137

\begin{abstract}
Emergency Rooms (ER) in hospitals are considered as an integral part of the health care system. The number of patients arriving to the ER constitutes a significant percentage of the total patients who demand health services from a hospital. Therefore insuring the ER services around the hour is very crucial to maximize patients' care. In addition, the efficient allocation and utilization of nurses and physicians is one of the most important issues facing ER administrators. Although demand on ER services in hospitals at Baghdad increases dramatically at certain incidents, we observed that the ERs, where we conducted the study, are overstaffed with nurses and physicians around the day. However, it is, always, desirable to operate any emergency room with minimum staff, while maintaining the quality of patient care. This paper simulates the patients' arrivals to determine the adequate number of nurses and physicians, required, over 24 hours, at the ERs of two large public hospitals at the city of Baghdad. The simulation results were adjusted and used to determine the number of physicians and nurses in each ER for one week, 3-shift working day. The analysis conducted in this paper revealed that it is possible to downsize the current number of physicians by an average of $28 \%$, and the number of nurses by about 55\% while maintaining emergency services around the hour. The results could be translated into lower operating expenses of the ER, and better utilization of staff resources in other parts of the hospital.
\end{abstract}

Keywords: Nurse Scheduling, Employee Scheduling, Simulation, Emergency Room

\section{Introduction}

Krajewski et al. (2007) indicate that scheduling is the allocation of resources over a period of time to accomplish specific tasks. In general, there are three types of scheduling: operations scheduling, demand scheduling, and personnel scheduling. Scheduling operations is a process in which jobs are assigned to workstations, or employees are assigned to jobs for a specified period of time. Demand scheduling is a process whereby customers are assigned to a definite time for order fulfillment, while a personnel scheduling determines when employees work. Stevenson (2002) states that it is important to note that scheduling customers is a type of demand management, but scheduling personnel is a process of capacity management. According to Reid and Sanders (2002) demand in service organizations, such as hospitals, is highly variable and cannot be scheduled, therefore administrators have to try alternatives to manage capacity such as: staff for peak demand, use floating personnel, hire personnel on call, employ part time personnel, use temporary personnel, or use a combination of these alternatives.

The scheduling of personnel has been tackled by managers, operations researchers, and computer scientists for long time. Scheduling personnel deals with different areas such as: short-term scheduling, budgeting, and staffing employees. Despite the fact that these areas cover different time horizons, they are all interrelated. 
Since hospitals are different from other organizations, the scheduling problem becomes a challenging one. Abernathy et al. (1971) stated that "The key element of effective nurse staffing is a well-conceived procedure for achieving an overall balance between the size of the nursing staff and the expected patient demand." Therefore, hospital administrators must try to create a good match between work loads and staffing requirements.

Staffing and scheduling of ER in hospitals becomes even more complicated because: ERs have to provide services 24 hours a day, scheduling has to take into consideration the nurses' and physicians' preferences, legal and work constraints have to be obeyed, and the quality of the ER services must always be present. Behavioral, social, seniority and status issues can always complicate the scheduling process in ERs. Thus Scheduling and staffing personnel to ERs is a difficult task.

In an early research, Warner (1976) identified three major decision areas of nurse scheduling: staffing, scheduling, and reallocation of nurses. He, also, suggested five criteria to judge nurse schedules:

Coverage: refers to the degree of similarity between the required and the scheduled staff.

Quality: refers to the fairness of the schedule in terms of length of time worked by each nurse.

Stability: measures the nurses' perception of the schedule in terms of predictable working and off days, and schedule consistency.

Flexibility: indicates the adaptability of the system to changes in the environment.

Cost: refers to the value of time consumed in making the schedule.

According to Centeno and Ismail (2003) a scheduling system has two concerns: minimizing the number of nurses to satisfy the required service level, and to develop a schedule such that everyone knows when to work while satisfying all work constraints. Evans (2002) describes the process of personnel scheduling by the following steps:

- $\quad$ Determining the amount of work to be performed

- $\quad$ Compute the staff required to do the work

- $\quad$ Determining the personnel availability

- $\quad$ Matching personnel to staffing requirements, and generate work

- $\quad$ Schedule

Moslieu et al. (2000) indicate that there are two main types of schedules: the rotating (cyclic) schedule and the noncylic schedules. In the rotating schedule all employees have the same basic schedule but start with different offsets. This type of schedules does not take personnel preferences into account, but it must cover the planning period. On the other hand, the noncylic schedule is one that takes into consideration the personnel preferences; the purpose is to generate schedules which fulfill employee preferences. Krajewski (2007) adds another type of a schedule which is the fixed schedule where each employee works the same day and the same hours every week, it is evident that this type of schedules does not take employee preferences into account.

Scheduling constraints are of two types: hard constraints and soft constraints. Hard constraints are those constraints that cannot be violated by hospital administrators. Such constraints my include coverage, working hours, off days and the like. Soft constraints, such as employee preferences, are those constraints that are desirable, but may be violated by the schedule.

As we indicated earlier, scheduling the workforce has been studied deeply by researchers using quantitative and qualitative approaches. Rosseti et al. (1999) state that the use of simulation in scheduling was not evident until the last decade. For instance Draeger (1992) introduced simulation models for three ER departments to study the nurse staffing concerns, and to assess some alternatives to improve nurse schedules. Other studies which employed simulations are conducted by Kamar and Kapur (1989), McGuire (1994), and Centeno and Ismail (2003) to mention some.

Hospitals, always, work under limited financial and human resources. Hospital administrators are expected to operate in an efficient and effective manner to provide quality health care to patients. Physicians and nurses are, also, expected to offer quality health care, contribute to organizational goals, and be satisfied with their working environment and profession.

During the past few years the Ministry of Health in Iraq has attempted to reduce costs and improve hospitals' performance. However, hospital administrators are often physicians and have no managerial experiences; therefore they need to use some tools and techniques to improve performance. The tool developed in this paper is easy to apply, and helps in determining the required staff of the ER for each shift of the day. The ERs studied in this work are overstaffed 
by physicians and nurses, and the total time of the staff available exceeds the required time to treat arriving patients. This phenomenon creates a case of staff underutilization which has a negative impact on the overall performance of the ER. In order to overcome this issue, it is important to evaluate the staffing and scheduling processes, at the ERs studied, to improve their performance by creating a match between the demand side (patients) and the required staff (capacity). To accomplish this, the authors shall simulate the arrival rate of three emergency rooms at two public hospitals at the city of Baghdad. These two hospitals are: Medicine City Hospital (east side of the Tigris River) with two emergency rooms, and Alkadimiya Hospital (west side of the Tigris River) with one emergency room. The results of the simulation are translated into service time requirements per shift, and are used to staff physicians and nurses for each shift of the day at the three emergency rooms. Repeatable (or fixed) weekly schedules are prepared for each ER. This approach is previously used in the studies of Cavouras (2002) and Spetz (2001).

This paper deals with an interesting topic that is not, often, tackled in the academic literature, and it offers some reflections to develop our understanding of the health care system. It also reveals some economic and managerial implications of overstaffed ERs in the medical field. The results of this work are useful for academicians, hospital administrators, and practitioners.

Section 2 of this paper provides a review of the literature pertinent to the staff scheduling problem. Section 3 introduces the research methodology. Section 4 provides a description of the ERs studied. Section 5 describes the data collection method. Sections 6 and 7 present a description of the simulation process, and the staffing and scheduling, respectively. Section 8 provides the findings and refers to some extensions of this effort.

\section{Literature Review}

Rossitti et al. (1999) indicate that the design and development of reliable schedules in ER has been widely studied in the literature since the 1960s. Many approaches were developed in the past five decades. These approaches included optimization techniques, goal programming and multiple criteria programming, artificial intelligence, heuristics, and metaheuristics. Warner and Prawda (1972) developed a linear programming model that generates short-run nurse schedules. According to the authors, the model: determines the nurses of each skill class to be assigned, satisfies total nursing capacity constraints, allows limited substitution of task among nurses, and minimizes the cost of nursing shortage during the scheduling period. Trivede and Warner (1976) proposed a branch-and-bound algorithm to assign "float nurses" from different sections in the hospital to wherever a shortage exists. Their work is considered the first to model nurse scheduling problem. The authors claim that the assignment of floating nurses plays an important role in modern hospital. However, the model deals with small-scale problems. Kostreva, Leszynski, and Passini (1978) used the mixed integer programming to develop nurse schedules. Arthur and Ravindran (1981) studied the nurse scheduling problem from a multiple objective point of view. They proposed a two phase goal programming heuristic to schedule nurses. The authors attempted in their heuristic to minimize, simultaneously, the staff size and the deviations between scheduled and desired staffing level. However, the approach was not successful in real world problems. A general mathematical model to solve the nurse scheduling problem was developed by Bailey and Field (1985), they proposed a twelve hour scheduling period as opposed to the eight hours shift, also their model permits the working shifts to start at any time. An integer programming tool was developed by Rosenbloom and Goertzen (1987) to tackle the problem of cyclical scheduling. This approach consists of three stages. The first stage generates a group of possible schedules, the second solves daily coverage constraints via an integer program, and the third stage accommodates the solution to the work pattern of each nurse. A goal programming model for a decision support was proposed by Ozkarahan (1991). The model attempts to minimize the over and understaffing of personnel while maximizing the utilization of full time personnel. Sitompul (1992) applied a heuristic-based Decision Support System to develop nurse schedules. Darmoni et al. (1995) developed software to schedule nurses in a large hospital. Their technique "Horoplan" takes into consideration scheduling constraints, and is practical and useful for short term decisions, but is unfit when high flexibility in schedules is required. An interactive program which is based on constraint programming was presented by Abdennadher and Schlenker (1999). The authors claim that the system was applied successfully in a real hospital situation. Muslija et al. (2000) believe that rotation of employees' schedules is beneficial for employees' health and satisfaction, and can improve the workforce performance. They, therefore, proposed a method to solve general workforce scheduling problems. According to the authors, the method takes into consideration personnel preferences and constraints. Carter and Lapierre (2001) studied the problem of scheduling ER physicians in six hospitals in Montreal, Canada. They conducted several interviews with physicians to get an insight of the ER scheduling problem. They, then, developed techniques to produce good schedules in a very short time. Centeno and Ismail (2003) mention that hospitals face pressures to control costs, and that the cost of staff constitutes a significant portion of the hospital's operating costs. They developed a method that incorporates a simulation model and an integer linear program. The purpose of their method was to prepare staffing requirements and to produce optimal schedules for the staff. Based on successful applications of the Ant Colony 
Optimization (ACO) in many constraint problems, Gutjahr and Rauner (2004), applied this technique to scheduling nurses to public hospitals in Vienna. The authors evaluated three scenarios by varying the number of nurses and hospitals for different demand levels, and by conducting extensive computational experiments; they demonstrated that the ACO improves significantly nurses' schedules in the public hospitals studied. Gendreau et al, (2006) benefited from the instances they encountered in six ER of different hospitals in Montreal, Canada. After reviewing certain solution tools (tabu search, column generation, mathematical programming and constraint programming), they examined the suitability of applying each one of these tools based on the conditions of each ER. They reported that no one tool proved suitable for all the ERs studied due to the constraints imposed on each situation. Kozan and Diefenbach (2008) stated that simulation is an important tool in resource analysis for hospitals emergency departments. Their study investigated the potential impacts of changing some factors relative to ER such as: physical layouts, number of beds, hospital staffing arrangement, etc. They reported that varying the magnitude of some factors has a clear effect on the system's variables.

The literature of nurse staffing and scheduling is immense and covers a wide spectrum of optimization models, heuristics, and approaches that were devoted to handle the nurse scheduling problem. In this work it is not possible to review all the literature available; however, the great body of research work in this area is an indicator of the significance of the nurse scheduling problem which makes it a good area to study and to conduct researches. One important point that can be concluded from the literature review is that few approaches are applicable to real life problems, we; therefore, believe that this topic shall continue to attract scientists and researchers in the future.

\section{Research Methodology}

A case study methodology was used in this work to obtain a feedback about the number of physicians and nurses needed to staff these ERs. The authors started by field observations and interviews with the personnel at the three ERs to understand the work process and to collect information about the staffing and the scheduling processes. Data on the arrival rate of patients were gathered using ER's records for the period between April-July 2009. Empirical distributions were used to describe the arrival distribution of patients. Based on the simulation results of patients' arrival and the adjustment made by ER administrators, the staffing requirements for nurses and physicians at each ER were calculated for three shifts/day. The actual staffing and the required staff for each ER, revealed by simulation, were compared to assist the hypothesis that the ERs were overstaffed. Finally, repeatable physicians' and nurses' schedules were developed manually for one week for each ER.

\section{Description of the ERs Studied}

The study covered three ERs, ER1 (27 beds) is part of AlKadimmiya Teaching Hospital situated at the west side of the capitol Baghdad. It receives different emergency cases. The second and the third ERs (ER2 \& ER3) are part of Baghdad Teaching Hospital situated at the east side of Baghdad. ER2 (28 beds) is a surgical ER which is designed to receive casualty cases (work accidents, burns, car accidents, injuries, and so forth). ER3 (24 beds) is a medical ER which is designed to receive patients with cardiac problems, blood clots, blood pressure, severe digestive problems and so forth. Physicians and nurses work side by side to rescue the life of patients. The maximum average time required to treat each patient is estimated by the staff of the ERs to be 40 minutes.

Each ER works 24 hours/day with three shifts: 8-4 (day shift), 4-12 (afternoon shift), and 12-8 (night shift). Table (1) presents the number of physicians and nurses currently staffed at each ER, while Table (2) shows how physicians and nurses are scheduled during the day at the three ERs. All physicians and nurses working at these ERs are employed on a full time basis, each one works for 40 hours/week, one shift/day, five days/week, and two days off/week.

Patients enter the ER by one of two methods: walk-in, or ambulance. When a walk-in patient arrives at the ER, a clerk registers information about the patient by filling out a special form. Depending on the patient's case, he or she is either admitted directly to the ER or is sent to a waiting room. If a patient is directed to a waiting room, then a triage nurse takes the patient's blood pressure, heart beat, temperature, etc. The patient is admitted to the ER when a bed is available. A physician assesses the patient's condition and then recommends the necessary treatment. When the patient's condition becomes stable, he/she is either designated to a wing inside the hospital or leaves the hospital. Patients arriving by ambulance bypass the registration process and are admitted to the ER directly, then they follow the same process of a walk-in patient.

Patient's arrival characteristics may be described as follows:

a) The arrival, the diagnosis, and the treatment of patients are unscheduled.

b) There exists no pattern to describe the arrival distribution of patients.

c) All cases arriving must be treated. 
d) Patients are triaged and seen according to their needs.

e) The treatment of a patient may be interrupted by a higher priority patient.

f) Past data about patients are not kept at the ERs studied.

g) The path followed by each patient is unique and depends on the patient's symptoms.

\section{Data Collection}

In order to construct empirical distributions of patient's arrivals, the authors depended on the ER's record and their personal observations from April 6th to July 15th, 2009. Table (3) presents a portion of our observations about patient's arrivals from April 6th - 16th, for 24 hours at ER2. Similar tables were prepared for the other ERs, and for the same period of study. Since the ERs studied do not have an idea about the arrival distributions of patients, we, therefore, transformed the data collected into hourly empirical distributions in order to use them to simulate patients' arrivals. Thus 72 (3 ERs $\times 24$ hours) empirical distributions were developed and used in the simulation process. Tables (4), and (5) present a sample of those distributions for ER2.

\section{Simulation of Patients' Arrival}

Operations research provide a bundle of analytical models, however, these models cannot easily represent the complex interactions created by random events. Therefore, simulation is used as a powerful tool for the operation and the design of complex systems. The purpose of the simulation of patients' arrival, developed in this paper, is to provide an insight about the behavior of the emergency arrivals, which is later used in staffing the ERs for three working shifts. Based on the 72 empirical distributions of patients' arrivals ( 24 distributions for each ER) prepared earlier, and by using Excel Spreadsheet (Excel 2003) the patients' arrival/hour was simulated for 100 days (or 100 replications). At the end of the replications, the average number of patients' arrival was computed for each hour, and was transformed into staff requirements. Table (6) provides a comparison of available and required treatment times at ER2 during three shifts based on the simulated arrival of patients (column 9), while Figure (1) presents a schematic comparison of the required and available time. From Figure (1) it appears that the available time (or capacity measured in time) exceeds dramatically the required treatment time. The same phenomenon was observed when the other ERs were simulated. Tables (7), (8), and (9) provide summaries of the simulation results for the three ERs studied. The staff requirement for each hour is determined by multiplying the average number of patients by 0.67 (40 minutes treatment per patient $\div 60$ minutes). For instance, and with reference to Table (7), row one, the staff requirements for that hour is approximately three $(4 \times 0.67)$. In similar manner, the staff requirements for each hour appearing on Tables (7)-(9) were computed.

\section{Staffing and Scheduling the ERs Studied}

In order to staff each shift in each ER by physicians and nurses, we had to consider the largest team size revealed by the simulation results in each shift to accommodate for the highest expected patient arrival. The appropriate team sizes are the underscored figures in Tables (7)-(9). When these results were presented to hospital administrators they expressed their concern about staffing two more personnel (one physician + one nurse) to improve patient's care in each work shift. The team size that should be on duty in each shift must correspond to the adjusted team sizes. However, taking into consideration the two days off constraint, imposed on the physician's and nurses' schedules, the total number of physicians and nurses required by the schedules should account for two days off/week/worker. This was translated into additional staff to satisfy this constraint. The required staffs reached by the simulation and the adjusted staff requirements at each ER during three shifts are expressed by Table (10). Table (11) and Table (12) present a possible one-week repeatable schedule for nurses and physicians at ER1. Similar schedules were, manually, prepared for the other ERs studied. When the proposed schedules were discussed with hospital administrations, we obtained a good feedback on them in terms of: coverage, fairness, stability, and low cost. Table (13) presents a comparison between the current staff and final staff reached in this study. The table also reflects the possible reductions in the number of physicians and nurses at the ERs studied.

\section{Conclusions}

This paper has dealt with a staffing and scheduling problem in three public emergency rooms, and has reached to short term staffing plans and schedules. In general, it was found that the three ERs studied were overstaffed by physicians and nurses. The analysis revealed that it is possible to downsize the number of physicians and nurses significantly, while maintaining emergency services around the hour. We also demonstrated that the simulation of patients' arrival could be used to determine the staff size in emergency rooms. The proposed schedules have acceptable quality since they are characterized by: coverage, fairness, stability, and low cost. Despite the fact that the results of this study are limited to the ERs studied, we believe that it is possible to use the same methodology to develop short term staffing plans and 
schedules in other ERs. The possibility of sensitivity analysis is limitless, for instance simulation of patients' arrival may be executed using other statistical distributions such as poison distribution to evaluate the impact of statistical distribution on the staffing decisions. Likewise, the simulation can be executed with different service times to decide on the staff needed when the service time changes. The simulation of patient arrival can assist ER administrators to respond more quickly in developing schedules and implementing them to facilitate coordination of staff allocation.

The present paper contributes to the field of physician and nurse scheduling because it has introduced an interesting topic that is not, often, tackled in the academic literature, and because it augments our understanding of the health care system. Downsizing the staff of ERs and maintaining quality health care around the hour imply cost benefits and performance improvements. We believe that this area shall continue to attract academicians, hospital administrators, and practitioners in the future.

\section{References}

Abdennadher, S. \& Schlenker, H. (1999). INTERDIP-An Interactive Constraint Based Nurse Scheduler in Proceedings, Practical Applications Constraint Technology and Logic Programming. PACLP99,London,UK..

Abernathy, W., Baloff, N. \& Hershey, J. (1971). The Nurse Staffing Problem: Issues and Prospects. Sloan Management Review, (13)1. 87-89.

Arthur, J. L. \& Ravindran, A. (1981). A Multiple Objective Nurse Scheduling Model. AIIE Transactions, (13)1, 55-60.

Bailey, J., \& Field, J. (1985). Personnel Scheduling with Flexshift Models. Journal of Operations Management, (5) 327-338. doi:10.1016/0272-6963(85)90017-8, http://dx.doi.org/10.1016/0272-6963(85)90017-8

Carter, M. W., \& Lapeierre, S. D. (2001). Scheduling Emergency Room Physicians. Health Care Management Science, (4), 347-360. doi:10.1023/A:1011802630656, http://dx.doi.org/10.1023/A:1011802630656

Cavouras, C.A. (2002). Nurse Staffing Levels in American Hospitals: A 2001 Report. Journal of Emergency Nursing,(28)1, 40-43. doi:10.1067/men.2002.121871, http://dx.doi.org/10.1067/men.2002.121871

Centeno, M. A. \& Ismail, A. M. (2003). A Simulation-ILP Based Tool for Scheduling ER Staff. S. Chick, P. J. Sánchez, D. Ferrin, \& D. J. Morrice, (eds.). Proceedings of the Winter Simulation Conference, New Orleans, USA, pp. 1930-1938.

Darmoni, S. J., Fajner, A., Mahe, N., Leforestier, A., Stelian, O., Vondracek, M., \& Baldenweck, M. (1995). Horoplan: Computer assisted Nurse Scheduling Using Constraint Based Programming.

Draeger, M. (1992). An emergency department simulation model used to evaluate alternative Nurse staffing and patient population scenarios. in J. J. Swain, D. Goldsman, R. C. Crain, \& J. R. Wilson (eds.), Winter Simulation Conference Proceedings, IEEE, Arlington, VA., pp. 1057-1064.

Evans, James R. (2002). Operations Management: Quality, Performance, and Value. (5 ${ }^{\text {th }}$ ed.), New York: West Publishing Company.

Gendreau, M. J., Ferl, J., Gendron, B., Hail, N., Jaumard, B., Lapierre, S., Pesant, G. \& Soriano, P. (2006). Physician Scheduling in Emergency Rooms, in E. K. Burke, H. Rudova (eds.), PATAT, 2006, pp. 2-14.

Gutjahr, W. J., \& Rauner, M. S. (2007). An ACO algorithm for a Dynamic Regional Nurse-Scheduling Problem in Austria. Journal of Computers and Operations Research, (37), 642-666.

Kostreva M., Leszcynski M., \& Passini, F. (1978). The Nurse Scheduling Decision via Mixed-Integer Programming. Proceedings of the American Hospital Association Forum on Nurse Scheduling, 291-305.

Kozan, E., \& Diefenbach, M. (2008). Hospital Emergency Simulation for Resource Analysis. IEMS, (7)2, 133-142.

Krajewski, L. J., Ritzman, L. P., \& Malhotra, M. K. (2007). Operations Management, Process and Value Chain, $\left(8^{\text {th }}\right.$ ed.), New Jersey: Prentice-Hall.

Kumar, A., \& Kapur, R. (1989). Discrete Simulation Application - Scheduling Staff for the Emergency Room. In E. A. MacNair, K. J., Musselman, \& P. Heidelberger (eds.) Winter Simulation Conference Proceedings, IEEE, Washington, DC, USA, 1112-1120

McGuire, F. (1994). Using Simulation to Reduce Length of Stay in Emergency Departments. In J.D. Tew, S. Manivannan, D.A. Sadowski, \& A.F. Seila (eds.), Winter Simulation Conference Proceedings, IEEE, Orlando, FL. USA, 861-867. 
Muslija, N., Gaertner J., \& Slany, W. (2000). Efficient generation of rotating workforce schedules. in E. K. Burke and W. Erben (eds.) Proceedings of the 3rd International Conference on the Practice and Theory of Automated Timetabling, Constance, Germany, 314-332.

Ozkarahan, I., (1991). An Integrated Nurse Scheduling Model. Journal of the Society for Health Systems, (3)2, 79-101.

Reid, R. D., \& Sanders, N. R. (2002). Operations Management, ( $1^{\text {st }}$ ed.), New York: John Wiley and Sons.

Rosenbloom, E. S., \& Goertzen, N. F., (1987). Cyclic Nurse scheduling. European Journal of Operational Research, (31)1, 19-23. doi:10.1016/0377-2217(87)90131-7, http://dx.doi.org/10.1016/0377-2217(87)90131-7

Rossetti, M.D., Trzcinski, G. G., \& Syverud, S. A. (1999). Emergency Department Simulation and Determination of Attending Physicin Staffing Schedules. in P. A. Farrington, H. B. Nembhard, D. T. Sturrock, \& G. W. Evans (eds.), Proceedings of the 1999 Winter Simulation Conference, Phoenix, Arizona, USA, 1532-1540.

Sitompul, D. (1992). Design and Implementation of a Heuristic-Based Decision Support System for Nurse Scheduling, Unpublished Doctoral Thesis, Oregon State University.

Spetz, J. (2001). Revised cost estimates of minimum nurse-to-patient ratio proposals. San Francisco, CA: Public Policy Institute of California, UCSF Center for the Health Professions.

Stevenson, W. J., (2002). Operations Management, ( $7^{\text {th }}$ ed.), Boston: McGraw-Hill Irwin.

Trivedi, V. M., \& Warner, M. (1976). A Branch and Bound Algorithm for Optimum Allocation of Float Nurses. Management Science, (22)9, 972-981. doi:10.1287/mnsc.22.9.972, http://dx.doi.org/10.1287/mnsc.22.9.972

Warner, D., \& Prawda, J., (1972). A Mathematical Programming Model for Scheduling Nursing Personnel in a Hospital. Management Science, (19)4, 411-422. doi:10.1287/mnsc.19.4.411, http://dx.doi.org/10.1287/mnsc.19.4.411

Warner, M. (1976). Nurse staffing, scheduling, and reallocation in the hospital. Hospital \& Health Services Administration, (21)3, 77-90.

Table 1. Current number of physicians and Nurses

\begin{tabular}{|c|c|c|}
\hline ER & Physicians & Nurses \\
\hline 1 & 19 & 24 \\
\hline 2 & 13 & 32 \\
\hline 3 & 15 & 30 \\
\hline
\end{tabular}

Table2. Scheduling Physicians and Nurses at the three ERs Studied

\begin{tabular}{|c|c|c|c|c|c|c|}
\hline \multirow{2}{*}{ Shift } & \multicolumn{2}{|c|}{ ER1 } & \multicolumn{2}{c|}{ ER2 } & \multicolumn{2}{c|}{ ER3 } \\
\cline { 2 - 7 } & Physicians & Nurses & Physicians & Nurses & Physicians & Nurses \\
\hline $8-4$ & 5 & 10 & 5 & 12 & 3 & 12 \\
\hline $4-12$ & 4 & 4 & 3 & 5 & 3 & 5 \\
\hline $12-8$ & 4 & 4 & 3 & 5 & 3 & 5 \\
\hline Total & 13 & 18 & 11 & 22 & 9 & 22 \\
\hline
\end{tabular}


Table 3. Sample Patients' Arrival at ER2 by Hours between 4/6-4/16

\begin{tabular}{|c|c|c|c|c|c|c|c|c|c|c|c|c|}
\hline & Date & $4 / 6$ & $4 / 7$ & $4 / 8$ & $4 / 9$ & $4 / 10$ & $4 / 11$ & $4 / 12$ & $4 / 13$ & $4 / 14$ & $4 / 15$ & $4 / 16$ \\
\hline & Day & $\mathrm{M}$ & $\mathrm{T}$ & W & $\mathrm{T}$ & $\mathrm{F}$ & $\mathrm{S}$ & $\mathrm{S}$ & $\mathrm{M}$ & $\mathrm{T}$ & $\mathrm{W}$ & $\mathrm{T}$ \\
\hline \multirow{24}{*}{ 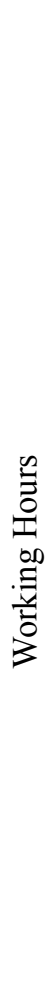 } & $8 \mathrm{am}$ & 3 & 2 & 6 & 4 & 1 & 9 & 0 & 1 & 4 & 1 & 2 \\
\hline & 9 & 8 & 0 & 2 & 6 & 4 & 10 & 4 & 2 & 2 & 4 & 3 \\
\hline & 10 & 2 & 4 & 6 & 4 & 6 & 3 & 4 & 1 & 5 & 4 & 4 \\
\hline & 11 & 3 & 10 & 4 & 5 & 6 & 7 & 6 & 2 & 6 & 7 & 4 \\
\hline & 12 & 1 & 1 & 2 & 3 & 4 & 1 & 5 & 4 & 9 & 6 & 8 \\
\hline & $1 \mathrm{pm}$ & 16 & 2 & 3 & 4 & 6 & 2 & 5 & 2 & 1 & 2 & 7 \\
\hline & 2 & 5 & 3 & 6 & 5 & 11 & 4 & 1 & 4 & 2 & 3 & 4 \\
\hline & 3 & 3 & 2 & 6 & 3 & 2 & 6 & 8 & 4 & 4 & 5 & 2 \\
\hline & 4 & 2 & 4 & 3 & 2 & 6 & 6 & 4 & 7 & 8 & 2 & 5 \\
\hline & 5 & 6 & 3 & 2 & 3 & 0 & 5 & 1 & 5 & 4 & 5 & 2 \\
\hline & 6 & 6 & 1 & 6 & 8 & 3 & 12 & 8 & 4 & 4 & 4 & 8 \\
\hline & 7 & 2 & 4 & 2 & 4 & 7 & 2 & 5 & 3 & 3 & 4 & 9 \\
\hline & 8 & 4 & 5 & 1 & 4 & 7 & 6 & 5 & 4 & 6 & 4 & 8 \\
\hline & 9 & 5 & 3 & 5 & 5 & 3 & 3 & 6 & 4 & 2 & 6 & 8 \\
\hline & 10 & 2 & 10 & 5 & 4 & 8 & 7 & 2 & 7 & 6 & 6 & 6 \\
\hline & 11 & 2 & 8 & 0 & 8 & 7 & 3 & 4 & 1 & 2 & 3 & 6 \\
\hline & 12 & 0 & 1 & 1 & 1 & 1 & 0 & 2 & 0 & 1 & 2 & 0 \\
\hline & $1 \mathrm{am}$ & 1 & 4 & 1 & 1 & 1 & 0 & 1 & 2 & 3 & 1 & 0 \\
\hline & 2 & 0 & 2 & 0 & 1 & 0 & 0 & 1 & 3 & 1 & 4 & 2 \\
\hline & 3 & 0 & 1 & 0 & 1 & 0 & 0 & 0 & 0 & 1 & 2 & 0 \\
\hline & 4 & 0 & 0 & 2 & 0 & 0 & 0 & 0 & 0 & 2 & 4 & 0 \\
\hline & 5 & 0 & 0 & 1 & 1 & 0 & 0 & 0 & 3 & 0 & 0 & 3 \\
\hline & 6 & 7 & 0 & 2 & 2 & 1 & 2 & 1 & 6 & 1 & 10 & 0 \\
\hline & 7 & 2 & 1 & 3 & 2 & 0 & 0 & 3 & 6 & 3 & 8 & 3 \\
\hline
\end{tabular}

Table 4. Empirical Distribution of Arrival Rate at ER2 from 8 -9 am

\begin{tabular}{|c|c|c|c|}
\hline $\mathrm{X}$ & $\mathrm{f}$ & $\mathrm{f}(\mathrm{x})$ & $\mathrm{F}(\mathrm{x})$ \\
\hline 0 & 15 & 0.15 & 0.15 \\
\hline 1 & 17 & 0.17 & 0.32 \\
\hline 2 & 24 & 0.24 & 0.56 \\
\hline 3 & 18 & 0.18 & 0.74 \\
\hline 4 & 12 & 0.12 & 0.86 \\
\hline 5 & 4 & 0.04 & 0.9 \\
\hline 6 & 4 & 0.04 & 0.94 \\
\hline 7 & 3 & 0.03 & 0.97 \\
\hline 8 & 1 & 0.03 & 1 \\
\hline
\end{tabular}

Table 5. Empirical Distribution of Arrival Rate at ER2 from 9 -10 am

\begin{tabular}{|c|c|c|c|}
\hline $\mathrm{X}$ & $\mathrm{f}$ & $\mathrm{f}(\mathrm{x})$ & $\mathrm{F}(\mathrm{x})$ \\
\hline 2 & 20 & 0.2 & 0.28 \\
\hline 3 & 16 & 0.16 & 0.44 \\
\hline 4 & 20 & 0.2 & 0.64 \\
\hline 5 & 12 & 0.12 & 0.76 \\
\hline 6 & 10 & 0.1 & 0.86 \\
\hline 7 & 5 & 0.05 & 0.91 \\
\hline 8 & 5 & 0.05 & 0.96 \\
\hline 10 & 4 & 0.04 & 1 \\
\hline
\end{tabular}


Table 6. Comparison of Available and Required Treatment Time at ER2 during Three Shifts

\begin{tabular}{|c|c|c|c|c|c|c|c|c|c|c|}
\hline & Period & $\begin{array}{c}\text { No. of } \\
\text { Physicians }\end{array}$ & $\begin{array}{l}\text { Available } \\
\text { Hours }\end{array}$ & $\begin{array}{l}\text { No. of } \\
\text { Nurses }\end{array}$ & $\begin{array}{l}\text { Available } \\
\text { Hours }\end{array}$ & $\begin{array}{l}\text { Total } \\
\text { Hours }\end{array}$ & $\begin{array}{l}\text { Total Time } \\
\text { in Minutes }\end{array}$ & $\begin{array}{c}\text { Simulated Average } \\
\text { Arrival } / \mathrm{Hr}\end{array}$ & $\begin{array}{c}\text { Treatment } \\
\text { Time/patient } \\
\text { (in Minutes) }\end{array}$ & $\begin{array}{c}\text { Total } \\
\text { Treatment } \\
\text { Time in Min. }\end{array}$ \\
\hline \multirow{8}{*}{$\begin{array}{l}\leftrightarrows \\
\Xi \\
+ \\
+\end{array}$} & 8 am to 8.59 & 3 & 3 & 12 & 12 & 15 & 900 & 3 & 40 & 120 \\
\hline & 9 to 9.59 & 3 & 3 & 12 & 12 & 15 & 900 & 4 & 40 & 160 \\
\hline & 10 to 10.59 & 3 & 3 & 12 & 12 & 15 & 900 & 5 & 40 & 200 \\
\hline & 11 to 10.59 & 3 & 3 & 12 & 12 & 15 & 900 & 6 & 40 & 240 \\
\hline & $12 \mathrm{pm}$ to 12.59 & 3 & 3 & 12 & 12 & 15 & 900 & 5 & 40 & 200 \\
\hline & 1 to 1.59 & 3 & 3 & 12 & 12 & 15 & 900 & 4 & 40 & 160 \\
\hline & 2 to 2.59 & 3 & 3 & 12 & 12 & 15 & 900 & 4 & 40 & 160 \\
\hline & 3 to 3.59 & 3 & 3 & 12 & 12 & 15 & 900 & 4 & 40 & 160 \\
\hline \multirow{8}{*}{ 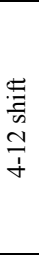 } & 4 to 4.59 & 3 & 3 & 5 & 5 & 8 & 480 & 3 & 40 & 120 \\
\hline & 5 to 5.59 & 3 & 3 & 5 & 5 & 8 & 480 & 3 & 40 & 120 \\
\hline & 6 to 6.59 & 3 & 3 & 5 & 5 & 8 & 480 & 4 & 40 & 160 \\
\hline & 7 to 7.59 & 3 & 3 & 5 & 5 & 8 & 480 & 4 & 40 & 160 \\
\hline & 8 to 8.59 & 3 & 3 & 5 & 5 & 8 & 480 & 4 & 40 & 160 \\
\hline & 9 to 9.59 & 3 & 3 & 5 & 5 & 8 & 480 & 5 & 40 & 200 \\
\hline & 10 to 10.59 & 3 & 3 & 5 & 5 & 8 & 480 & 4 & 40 & 160 \\
\hline & 11 to 11.59 & 3 & 3 & 5 & 5 & 8 & 480 & 3 & 40 & 120 \\
\hline \multirow{8}{*}{ 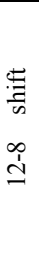 } & $12 \mathrm{am}$ to 12.59 & 3 & 3 & 5 & 5 & 8 & 480 & 2 & 40 & 80 \\
\hline & 1 to 1.59 & 3 & 3 & 5 & 5 & 8 & 480 & 1 & 40 & 40 \\
\hline & 2 to 2.59 & 3 & 3 & 5 & 5 & 8 & 480 & 1 & 40 & 40 \\
\hline & 3 to 3.59 & 3 & 3 & 5 & 5 & 8 & 480 & 1 & 40 & 40 \\
\hline & 4 to 4.59 & 3 & 3 & 5 & 5 & 8 & 480 & 1 & 40 & 40 \\
\hline & 5 to 5.59 & 3 & 3 & 5 & 5 & 8 & 480 & 1 & 40 & 40 \\
\hline & 6 to 6.59 & 3 & 3 & 5 & 5 & 8 & 480 & 2 & 40 & 80 \\
\hline & 7 to 7.59 & 3 & 3 & 5 & 5 & 8 & 480 & 2 & 40 & 80 \\
\hline
\end{tabular}

Table 7. Simulation Results: Average Arrival \& Team Size by Hours at ER1

\begin{tabular}{|c|c|c|c|}
\hline & Time & $\begin{array}{l}\text { Average } \\
\text { Arrival }\end{array}$ & $\begin{array}{l}\text { Team } \\
\text { Size }\end{array}$ \\
\hline \multirow{8}{*}{ 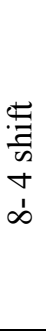 } & 8 to 9 am & 4 & 3 \\
\hline & 9 to 10 & 6 & 4 \\
\hline & 10 to 11 & 7 & $\underline{5}$ \\
\hline & 11 to 12 & 6 & 4 \\
\hline & 12 to $1 \mathrm{pm}$ & 5 & 3 \\
\hline & 1 to 2 & 4 & 3 \\
\hline & 2 to 3 & 3 & 2 \\
\hline & 3 to 4 & 3 & 2 \\
\hline \multirow{8}{*}{ 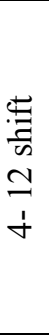 } & 4 to 5 & 3 & 2 \\
\hline & 5 to 6 & 4 & 3 \\
\hline & 6 to 7 & 4 & $\underline{3}$ \\
\hline & 7 to 8 & 4 & 3 \\
\hline & 8 to 9 & 4 & 3 \\
\hline & 9 to 10 & 4 & 3 \\
\hline & 10 to 11 & 3 & 2 \\
\hline & 11 to 12 & 2 & 1 \\
\hline \multirow{8}{*}{ 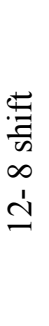 } & 12 to $1 \mathrm{am}$ & 2 & 1 \\
\hline & 1 to 2 & 1 & 1 \\
\hline & 2 to 3 & 0 & 0 \\
\hline & 3 to 4 & 0 & 0 \\
\hline & 4 to 5 & 1 & 1 \\
\hline & 5 to 6 & 1 & 1 \\
\hline & 6 to 7 & 1 & 1 \\
\hline & 7 to $8 \mathrm{am}$ & 3 & $\underline{2}$ \\
\hline
\end{tabular}


Table 8. Simulation Results: Average Arrival \& Team Size by Hours at ER2

\begin{tabular}{|c|c|c|c|}
\hline & Time & $\begin{array}{c}\text { Average } \\
\text { Arrival }\end{array}$ & $\begin{array}{l}\text { Team } \\
\text { Size }\end{array}$ \\
\hline \multirow{8}{*}{ 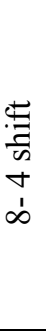 } & 8 to 9 am & 3 & 2 \\
\hline & 9 to 10 & 4 & 3 \\
\hline & 10 to 11 & 5 & 3 \\
\hline & 11 to 12 & 6 & $\underline{4}$ \\
\hline & 12 to $1 \mathrm{pm}$ & 5 & 3 \\
\hline & 1 to 2 & 4 & 3 \\
\hline & 2 to 3 & 4 & 3 \\
\hline & 3 to 4 & 4 & 3 \\
\hline \multirow{8}{*}{ 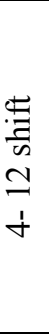 } & 4 to 5 & 3 & 2 \\
\hline & 5 to 6 & 3 & 2 \\
\hline & 6 to 7 & 4 & 3 \\
\hline & 7 to 8 & 4 & $\underline{3}$ \\
\hline & 8 to 9 & 4 & 3 \\
\hline & 9 to 10 & 5 & 3 \\
\hline & 10 to 11 & 4 & 3 \\
\hline & 11 to 12 & 3 & 2 \\
\hline \multirow{8}{*}{ 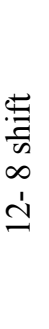 } & 12 to $1 \mathrm{am}$ & 2 & 1 \\
\hline & 1 to 2 & 1 & 1 \\
\hline & 2 to 3 & 1 & 1 \\
\hline & 3 to 4 & 1 & 1 \\
\hline & 4 to 5 & 1 & 1 \\
\hline & 5 to 6 & 1 & 1 \\
\hline & 6 to 7 & 2 & 1 \\
\hline & 7 to 8 am & 3 & $\underline{2}$ \\
\hline
\end{tabular}

Table 9. Simulation Results: Average Arrival \& Team Size by Hours at ER3

\begin{tabular}{|c|c|c|c|}
\hline & Time & $\begin{array}{c}\text { Average } \\
\text { Arrival }\end{array}$ & $\begin{array}{c}\text { Team } \\
\text { Size }\end{array}$ \\
\hline \multirow{8}{*}{$\begin{array}{l}\stackrel{\Xi}{\Xi} \\
\dot{\Xi} \\
\dot{\nabla} \\
\infty\end{array}$} & 8 to 9 am & 3 & 2 \\
\hline & 9 to 10 & 3 & 2 \\
\hline & 10 to 11 & 3 & 2 \\
\hline & 11 to 12 & 4 & $\underline{3}$ \\
\hline & 12 to $1 \mathrm{pm}$ & 3 & 2 \\
\hline & 1 to 2 & 3 & 2 \\
\hline & 2 to 3 & 3 & 2 \\
\hline & 3 to 4 & 3 & 2 \\
\hline \multirow{8}{*}{ 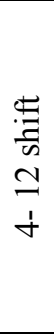 } & 4 to 5 & 3 & 2 \\
\hline & 5 to 6 & 3 & 2 \\
\hline & 6 to 7 & 3 & $\underline{2}$ \\
\hline & 7 to 8 & 3 & 2 \\
\hline & 8 to 9 & 3 & 2 \\
\hline & 9 to 10 & 3 & 2 \\
\hline & 10 to 11 & 3 & 2 \\
\hline & 11 to 12 & 2 & 1 \\
\hline \multirow{8}{*}{ 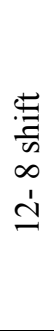 } & 12 to $1 \mathrm{am}$ & 1 & 1 \\
\hline & 1 to 2 & 1 & 1 \\
\hline & 2 to 3 & 1 & 1 \\
\hline & 3 to 4 & 1 & 1 \\
\hline & 4 to 5 & 1 & 1 \\
\hline & 5 to 6 & 0 & 0 \\
\hline & 6 to 7 & 1 & 1 \\
\hline & 7 to 8 am & 3 & $\underline{2}$ \\
\hline
\end{tabular}


Table 10. Simulated and Adjusted Staff

\begin{tabular}{|c|c|c|c|c|c|c|}
\hline & \multicolumn{6}{|l|}{ ER1 } \\
\hline & \multirow{2}{*}{$\begin{array}{l}\text { Simulated } \\
\text { Staff }\end{array}$} & \multicolumn{2}{|c|}{ Combination } & \multirow{2}{*}{$\begin{array}{l}\text { Adjusted } \\
\text { Staff * }\end{array}$} & \multicolumn{2}{|c|}{ Combination } \\
\hline & & Physicians & Nurses & & Physicians & Nurses \\
\hline $\begin{array}{c}8-4 \\
\text { shift }\end{array}$ & 5 & 2 & 3 & 11 & 5 & 6 \\
\hline 4-12 shift & 3 & 1 & 2 & 8 & 3 & 5 \\
\hline \multirow[t]{3}{*}{$12-8$ shift } & 2 & 1 & 1 & 6 & 3 & 3 \\
\hline & & & & Total & 11 & 14 \\
\hline & \multicolumn{6}{|l|}{ ER2 } \\
\hline $\begin{array}{c}8-4 \\
\text { shift }\end{array}$ & 4 & 2 & 2 & 10 & 5 & 5 \\
\hline $4-12$ shift & 3 & 1 & 2 & 8 & 3 & 5 \\
\hline \multirow[t]{3}{*}{$12-8$ shift } & 2 & 1 & 1 & 6 & 3 & 3 \\
\hline & & & & Total & 11 & 13 \\
\hline & \multicolumn{6}{|l|}{ ER3 } \\
\hline $\begin{array}{c}8-4 \\
\text { shift }\end{array}$ & 3 & 1 & 2 & 10 & 5 & 5 \\
\hline $4-12$ shift & 2 & 1 & 1 & 6 & 3 & 3 \\
\hline \multirow[t]{2}{*}{$12-8$ shift } & 2 & 1 & 1 & 6 & 3 & 3 \\
\hline & & & & Total & 11 & 11 \\
\hline
\end{tabular}

*Adjusted for better patient care, and for the two days off/worker constraint.

Table 11. One Week-Three Shifts Repeatable Nurse Schedule for ER1

\begin{tabular}{|c|c|c|c|c|c|c|c|c|}
\hline & & Sat & Sun & Mon & Tue & Wed & Thu & Fri \\
\hline \multirow{6}{*}{$\begin{array}{l}+ \\
\infty \\
\infty\end{array}$} & Nurse 1 & $\bar{X}$ & $\mathrm{X}$ & $\mathrm{X}$ & $\mathrm{X}$ & $\bar{X}$ & Off & Off \\
\hline & Nurse 2 & Off & Off & $\mathrm{X}$ & $\mathrm{X}$ & $\mathrm{X}$ & $\mathrm{X}$ & $\mathrm{X}$ \\
\hline & Nurse 3 & $\mathrm{X}$ & $\mathrm{X}$ & Off & Off & $\mathrm{X}$ & $\mathrm{X}$ & $\mathrm{X}$ \\
\hline & Nurse 4 & $\bar{X}$ & $\mathrm{X}$ & $\mathrm{X}$ & $\mathrm{X}$ & Off & Off & $\mathrm{X}$ \\
\hline & Nurse 5 & Off & $\mathrm{X}$ & $\mathrm{X}$ & $\mathrm{X}$ & $\mathrm{X}$ & $\mathrm{X}$ & Off \\
\hline & Nurse 6 & $\mathrm{X}$ & $\mathrm{X}$ & $\mathrm{X}$ & Off & Off & $\mathrm{X}$ & $\mathrm{X}$ \\
\hline \multicolumn{2}{|c|}{ Capacity Available } & 4 & 5 & 5 & 4 & 4 & 4 & 4 \\
\hline \multicolumn{2}{|c|}{ Capacity Requirement } & 4 & 4 & 4 & 4 & 4 & 4 & 4 \\
\hline \multicolumn{2}{|c|}{ Slack } & 0 & 1 & 1 & 0 & 0 & 0 & 0 \\
\hline \multirow{5}{*}{$\begin{array}{l}\stackrel{y}{7} \\
\frac{7}{4}\end{array}$} & Nurse 7 & $\mathrm{X}$ & $\mathrm{X}$ & $\mathrm{X}$ & $\mathrm{X}$ & $\mathrm{X}$ & off & off \\
\hline & Nurse 8 & Off & Off & $\mathrm{X}$ & $\mathrm{X}$ & $\mathrm{X}$ & $\mathrm{X}$ & $\mathrm{X}$ \\
\hline & Nurse 9 & $\mathrm{X}$ & $\mathrm{X}$ & Off & Off & $\mathrm{x}$ & $\mathrm{x}$ & $\mathrm{X}$ \\
\hline & Nurse 10 & $\mathrm{X}$ & $\mathrm{X}$ & $\mathrm{X}$ & $\mathrm{X}$ & Off & Off & $\mathrm{X}$ \\
\hline & Nurse 11 & Off & $\mathrm{X}$ & $\mathrm{X}$ & $\mathrm{X}$ & $\mathrm{X}$ & $\mathrm{X}$ & Off \\
\hline \multicolumn{2}{|c|}{ Capacity Available } & 3 & 4 & 4 & 4 & 4 & 3 & 3 \\
\hline \multicolumn{2}{|c|}{ Capacity Requirement } & 3 & 3 & 3 & 3 & 3 & 3 & 3 \\
\hline \multicolumn{2}{|c|}{ Slack } & 0 & 1 & 1 & 1 & 1 & 0 & 0 \\
\hline \multirow{3}{*}{ 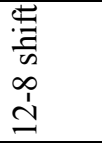 } & Nurse 12 & Off & Off & $\mathrm{X}$ & $\mathrm{X}$ & $\mathrm{X}$ & $\mathrm{X}$ & $\mathrm{X}$ \\
\hline & Nurse 13 & $\mathrm{X}$ & $\mathrm{X}$ & Off & Off & $\mathrm{X}$ & $\mathrm{X}$ & $\mathrm{X}$ \\
\hline & Nurse 14 & $\mathrm{X}$ & $\mathrm{X}$ & $\mathrm{X}$ & $\mathrm{X}$ & Off & Off & $\mathrm{X}$ \\
\hline \multicolumn{2}{|c|}{ Capacity Available } & 2 & 2 & 2 & 2 & 2 & 2 & 3 \\
\hline \multicolumn{2}{|c|}{ Capacity Requirement } & 2 & 2 & 2 & 2 & 2 & 2 & 2 \\
\hline \multicolumn{2}{|c|}{ Slack } & 0 & 0 & 0 & 0 & 0 & 0 & 1 \\
\hline
\end{tabular}


Table 12. One Week-Three Shifts Repeatable Physician Schedule for ER1

\begin{tabular}{|c|c|c|c|c|c|c|c|c|}
\hline & & Sat & Sun & Mon & Tue & Wed & Thu & Fri \\
\hline \multirow{5}{*}{$\begin{array}{l}+\stackrel{\leftrightarrows}{\leftrightarrows} \\
\infty \\
\infty\end{array}$} & Physician 1 & $\mathrm{X}$ & $\mathrm{X}$ & $\mathrm{X}$ & $\mathrm{X}$ & $\mathrm{X}$ & Off & Off \\
\hline & Physician 2 & Off & Off & $\mathrm{X}$ & $\mathrm{X}$ & $\mathrm{X}$ & $\mathrm{X}$ & $\mathrm{X}$ \\
\hline & Physician 3 & $\mathrm{X}$ & $\mathrm{X}$ & Off & Off & $\mathrm{X}$ & $\mathrm{X}$ & $\mathrm{X}$ \\
\hline & Physician 4 & $\mathrm{X}$ & $\mathrm{X}$ & $\mathrm{X}$ & $\mathrm{X}$ & Off & Off & $\mathrm{X}$ \\
\hline & Physician 5 & off & $\mathrm{X}$ & $\mathrm{X}$ & $\mathrm{X}$ & $\mathrm{X}$ & $\mathrm{X}$ & Off \\
\hline \multicolumn{2}{|c|}{ Capacity Available } & 3 & 4 & 4 & 4 & 4 & 3 & 3 \\
\hline \multicolumn{2}{|c|}{ Capacity Requirement } & 3 & 3 & 3 & 3 & 3 & 3 & 3 \\
\hline \multicolumn{2}{|c|}{ Slack } & 0 & 1 & 1 & 1 & 1 & 0 & 0 \\
\hline \multirow{3}{*}{$\frac{N}{\dot{f}} \stackrel{\leftrightarrows}{\varpi}$} & Physician 6 & Off & Off & $\mathrm{X}$ & $\mathrm{X}$ & $\mathrm{X}$ & $\mathrm{X}$ & $\mathrm{X}$ \\
\hline & Physician 7 & $\mathrm{X}$ & $X$ & Off & Off & $X$ & $X$ & $\mathrm{X}$ \\
\hline & Physician 8 & $\mathrm{X}$ & $\mathrm{X}$ & $\mathrm{X}$ & $\mathrm{X}$ & Off & Off & $\mathrm{X}$ \\
\hline \multicolumn{2}{|c|}{ Capacity Available } & 2 & 2 & 2 & 2 & 2 & 2 & 3 \\
\hline \multicolumn{2}{|c|}{ Capacity Requirement } & 2 & 2 & 2 & 2 & 2 & 2 & 2 \\
\hline \multicolumn{2}{|r|}{ Slack } & 0 & 0 & 0 & 0 & 0 & 0 & 1 \\
\hline \multirow{3}{*}{$\begin{array}{l}\infty \\
\stackrel{1}{1} \\
\stackrel{-}{n}\end{array}$} & Physician 9 & Off & Off & $\mathrm{X}$ & $\mathrm{X}$ & $\mathrm{X}$ & $\mathrm{X}$ & $\mathrm{X}$ \\
\hline & Physician 10 & $\mathrm{X}$ & $\mathrm{X}$ & Off & Off & $\mathrm{X}$ & $\mathrm{X}$ & $\mathrm{X}$ \\
\hline & Physician 11 & $X$ & $\mathrm{X}$ & $X$ & $\mathrm{X}$ & Off & Off & $\mathrm{X}$ \\
\hline \multicolumn{2}{|c|}{ Capacity Available } & 2 & 2 & 2 & 2 & 2 & 2 & 3 \\
\hline \multicolumn{2}{|c|}{ Capacity Requirement } & 2 & 2 & 2 & 2 & 2 & 2 & 2 \\
\hline \multicolumn{2}{|r|}{ Slack } & 0 & 0 & 0 & 0 & 0 & 0 & 1 \\
\hline
\end{tabular}

Table 13. Comparison of Current and Final Staff

\begin{tabular}{|c|c|c|c|c|c|c|}
\hline & \multicolumn{3}{|c|}{ Physicians } & \multicolumn{3}{|c|}{ Nurses } \\
\hline ER & Current & $\begin{array}{c}\text { Final } \\
\text { Staffed }\end{array}$ & Reduction & Current & Final Staffed & Reduction \\
\hline 1 & 19 & 11 & $42 \%$ & 24 & 14 & $42 \%$ \\
\hline 2 & 13 & 11 & $15 \%$ & 32 & 13 & $59 \%$ \\
\hline 3 & 15 & 11 & $27 \%$ & 30 & 11 & $63 \%$ \\
\hline \multicolumn{3}{|c|}{ Average } & $28 \%$ & \multicolumn{2}{|c|}{ Average } & $55 \%$ \\
\hline
\end{tabular}

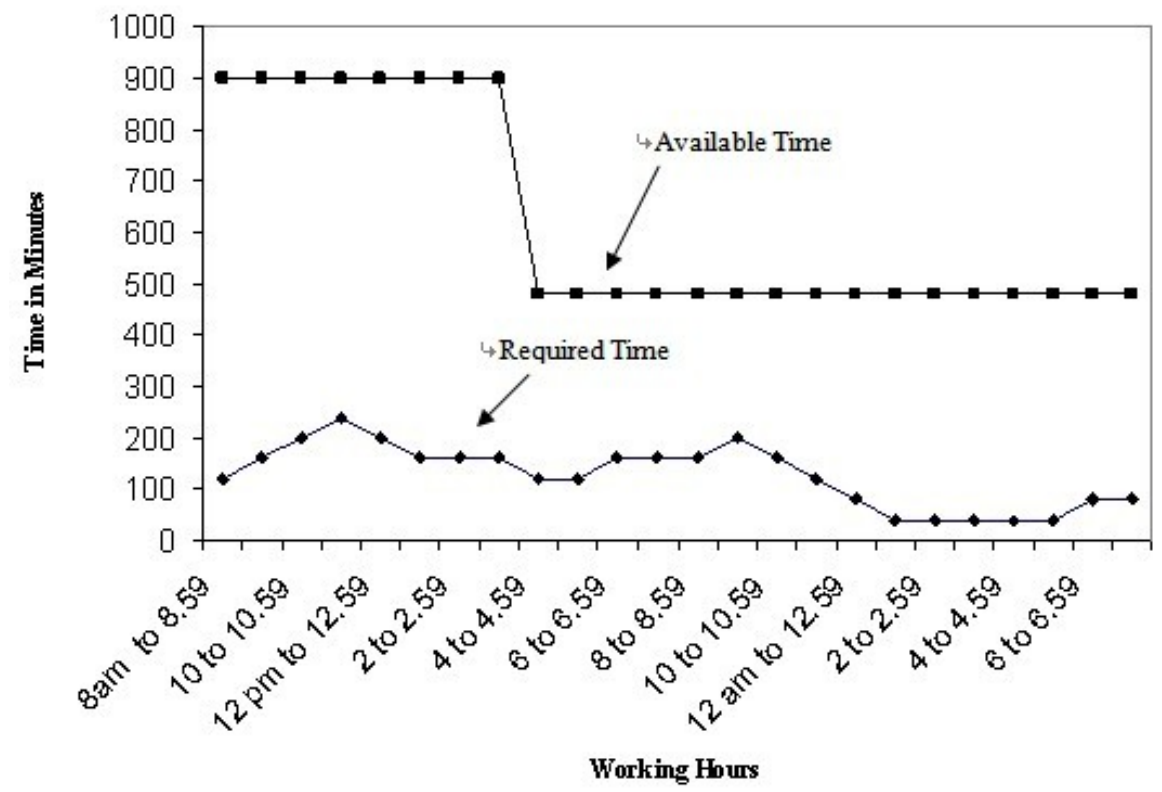

Figure 1. Comparison of Required and Available Treatment Time at ER2 during Three Shifts 